\title{
Changes in concentration and size distribution of aerosols during fog over the south Indian Ocean
}

\author{
Vimlesh Pant ${ }^{1}$, C G Deshpande and A K Kamra* \\ Indian Institute of Tropical Meteorology, Dr. Homi Bhabha Road, Pune 411 008, India. \\ ${ }^{1}$ Current Address: India National Centre for Ocean Information Services, Ocean Valley, Hyderabad 500055 , India. \\ *e-mail: kamra@tropmet.res.in
}

\begin{abstract}
Measurements of the concentration and size distribution of aerosol particles in the size-ranges of 0.5-20 $\mu \mathrm{m}$ and 16-700 $\mathrm{nm}$ diameters were made during six fog episodes over the south Indian Ocean. Observations show that concentrations of particles of all sizes start decreasing 1-2 hours before the occurrence of fog. This decrease is more prominent for coarse particles of $>1 \mu \mathrm{m}$ diameter and continues until 10-20 minutes before the onset of fog when particle concentrations in all size ranges rapidly increase by one/two orders of magnitude in $\sim 20$ minutes. Thereafter, concentrations of particles of all sizes gradually decrease until the dissipation of fog. After the fog dissipation, concentrations of coarse mode particles rapidly increase and restore to their pre-fog levels but concentrations of the Aitken mode particles decrease slowly and reach their pre-fog levels only after 1-2 hours. The net effect of fog is to change the bimodal size distributions of aerosols with a coarse mode at $1.0 \mu \mathrm{m}$ and an accumulation mode at $40-60 \mathrm{~nm}$ to a power law size distribution. It is proposed that the preferential growth and sedimentation of the coarse mode hygroscopic particles in the initial phase cause a large decrease in the aerosol surface area. As a result, the low vapour pressure gases which were initially being used for the growth of coarse mode particles, now accelerate the growth rates of the accumulation and Aitken mode particles.
\end{abstract}

\section{Introduction}

Occurrence of fog significantly changes the characteristics of aerosols through several physical and chemical processes involving nucleation of water vapour on particles, the Brownian diffusion and coagulation of aerosols, interaction of aerosols and fog, efficiency of heterogeneous reactions, scavenging of aerosols by fog droplets during their sedimentation to the ground, etc., (e.g., Ulevicius et al 1994; Sasakawa and Uematsu 2002; Sasakawa et al 2003; Moore et al 2004). Although, chemical properties of sea fog are rarely reported, size distribution measurements of the aerosol and fog particles can reveal about several aspects of the chemical properties and the physical and chemical processes involved in such events. The high-resolution data of ultrafine, fine and coarse aerosol particles obtained during the Pilot Expedition to Southern Ocean (PESO) and presented here provided an opportunity to understand the sequential changes in the aerosol characteristics that occurred during sea-fog episodes over the southern Indian Ocean.

\section{Instrumentation}

An Aerodynamic Particle Sizer (APS, TSI Model 3321) and a Scanning Mobility Particle Sizer (SMPS, TSI Model 3936) were used to measure the size distributions of particles in the size ranges of $0.5-20 \mu \mathrm{m}$ and $16-700 \mathrm{~nm}$ diameters, respectively. The air sample was drawn through a 3-m long Teflon tube of $4 \mathrm{~cm}$ diameter fixed in a window of the first cabin from the bow side on the forecastle deck of ORV Sagarkanya. The tube was inclined at

Keywords. Aerosol size distribution; sea fog; Indian Ocean; atmospheric sciences; aerosols. 
Table 1. Position and period of fog episodes and the average values of the meteorological parameters during the fog events.

\begin{tabular}{cccccrcr}
\hline $\begin{array}{l}\text { Date } \\
\text { February }\end{array}$ & $\begin{array}{c}\text { Position } \\
\text { (latitude, } \\
\text { longitude) }\end{array}$ & $\begin{array}{c}\text { Fog episode } \\
\text { period } \\
(\mathrm{UT})\end{array}$ & $\begin{array}{c}\text { Relative } \\
\text { humidity } \\
(\%)\end{array}$ & $\begin{array}{c}\text { Wind } \\
\text { direction } \\
(\text { degree })\end{array}$ & $\begin{array}{c}\text { Wind } \\
\text { speed } \\
\left(\mathrm{ms}^{-1}\right)\end{array}$ & $\begin{array}{c}\text { Air } \\
\text { temperature } \\
\left({ }^{\circ} \mathrm{C}\right)\end{array}$ & $\begin{array}{c}\text { Sea surface } \\
\text { temperature } \\
\left({ }^{\circ} \mathrm{C}\right)\end{array}$ \\
\hline 9 & $44.0^{\circ} \mathrm{S}, 45.1^{\circ} \mathrm{E}$ & $1200-1330$ & $92 \pm 3$ & $230 \pm 24$ & $9.0 \pm 2.4$ & $10.2 \pm 1.2$ & 9.1 \\
15 & $52.9^{\circ} \mathrm{S}, 45.0^{\circ} \mathrm{E}$ & $0440-0520$ & $96 \pm 2$ & $290 \pm 20$ & $4.7 \pm 1.8$ & $3.4 \pm 0.9$ & 2.3 \\
15 & $53.7^{\circ} \mathrm{S}, 45.0^{\circ} \mathrm{E}$ & $1440-1715$ & $93 \pm 3$ & $320 \pm 22$ & $7.5 \pm 2.6$ & $3.0 \pm 0.8$ & 2.2 \\
17 & $55.8^{\circ} \mathrm{S}, 45.0^{\circ} \mathrm{E}$ & $0900-1100$ & $87 \pm 4$ & $300 \pm 21$ & $6.9 \pm 3.1$ & $2.5 \pm 0.3$ & 1.9 \\
23 & $47.0^{\circ} \mathrm{S}, 57.5^{\circ} \mathrm{E}$ & $0830-0920$ & $96 \pm 1$ & $240 \pm 26$ & $8.5 \pm 3.4$ & $11.4 \pm 1.3$ & 9.2 \\
23 & $46.4^{\circ} \mathrm{S}, 57.5^{\circ} \mathrm{E}$ & $1430-1630$ & $96 \pm 2$ & $240 \pm 25$ & $15.2 \pm 3.5$ & $11.0 \pm 1.4$ & 9.2 \\
\hline
\end{tabular}

$45^{\circ}$ to the horizontal and its inlet faced the direction of motion of the ship. Inlet of the tube was located $2 \mathrm{~m}$ away from the body of the ship, $8 \mathrm{~m}$ downwind of bow of the ship and $10 \mathrm{~m}$ above the mean sea level. There was no tall structure to significantly distort the airflow between the inlet and bow of the ship. These efforts in positioning the tube were made in order to locate the inlet out of turbulent boundary layer created around the ship and collect the sample in free air. Other end of the tube terminated in a $30 \times 15 \times 15 \mathrm{~cm}$ reservoir box made out of galvanized iron sheet and fixed inside an air-conditioned cabin to keep it at a constant temperature. A fan fixed on a wall of the reservoir box sucked the air at $833 \mathrm{~L} \mathrm{~min}^{-1}$ which ensured an airflow of $11 \mathrm{~ms}^{-1}$ through the tube at all times. Comparatively large diameter of the Teflon tube reduced the diffusional losses of the particles to the walls of the tube. Since the flow rate in the tube and reservoir was much greater than the terminal velocity of the largest aerosol particle, particles would remain airborne and drift with the airflow, thus minimizing their loss by sedimentation or diffusion to the walls of the tube/reservoir. Moreover, the growth and loss of large hygroscopic particles by coagulation in the Teflon tube is not expected to be appreciable because the relative velocity between such large particles, say $10 \mu \mathrm{m}$ in diameter, and smallest particles will be only $0.003 \mathrm{~ms}^{-1}$. Moreover, particles will spend less than $0.1 \mathrm{~s}$ in the tube. Loss of particles in our experimental set-up is discussed in detail by Pant et al (2008, 2009). Comparative measurements conducted in our observatory at Pune, India, with and without the Teflon tube and reservoir box attached to the systems showed that the total particle concentrations did not differ by $>8 \%$, thus confirming that the tube and reservoir box made no appreciable change in the collection efficiency of the system.

Air samples for the APS and SMPS systems were drawn through individual silicon conductive tubes of $0.5 \mathrm{~cm}$ diameter fixed on one side of the reservoir box. Details of the experimental set-up including various sources of error and the measures taken to minimize the errors, are discussed in Pant et al (2008).

The inlet tube was fixed $25 \mathrm{~m}$ upwind of the ship's smoke stack to minimize the chances of smoke from the ship's stack contaminating the sampled air. There was no other exhaust located on the upwind side of the sampling tube. An automatic weather station with its sensors fixed at $10 \mathrm{~m}$ above sea level, was used to make meteorological measurements.

\section{Fog episodes}

Six episodes of fog occurred south of $44^{\circ} \mathrm{S}$ along the cruise route of the PESO during January 23 and March 31, 2004. Table 1 shows the approximate timings from visual observations and other details of episodes. In all events the relative humidity is $>87 \%$, wind speeds are westerly and $>4.7 \mathrm{~ms}^{-1}$ and the sea surface temperature is lower by 0.6 to $2.2^{\circ} \mathrm{C}$ than the overlying air showing that a warm moist air lies above a cold surface. Further, the 5-day backward trajectories drawn in figure 1 from HYSPLIT transport and dispersion model of NOAA Air Resource Laboratory, examined from approximately one hour before to one hour after the fog periods, did not change significantly except for the case of the forenoon on February 23, 2004 when the airmass arrived from $44.7^{\circ} \mathrm{S}, 43.3^{\circ} \mathrm{E}$ before, but from $31.6^{\circ} \mathrm{S}, 72.7^{\circ} \mathrm{E}$ after the fog period. On this day, altitude history of backward trajectories prior to $\sim 2.5$ days before and after their arrival at Maitri, also differed significantly (figure 1). In all cases, however, the airmass remained of marine origin.

\section{Results}

\subsection{Number size distribution of particles}

In the following description, particles have been categorized in nucleation mode $(d \leq 0.02 \mu \mathrm{m})$, Aitken mode $(0.02<d<0.1 \mu \mathrm{m})$, accumulation 

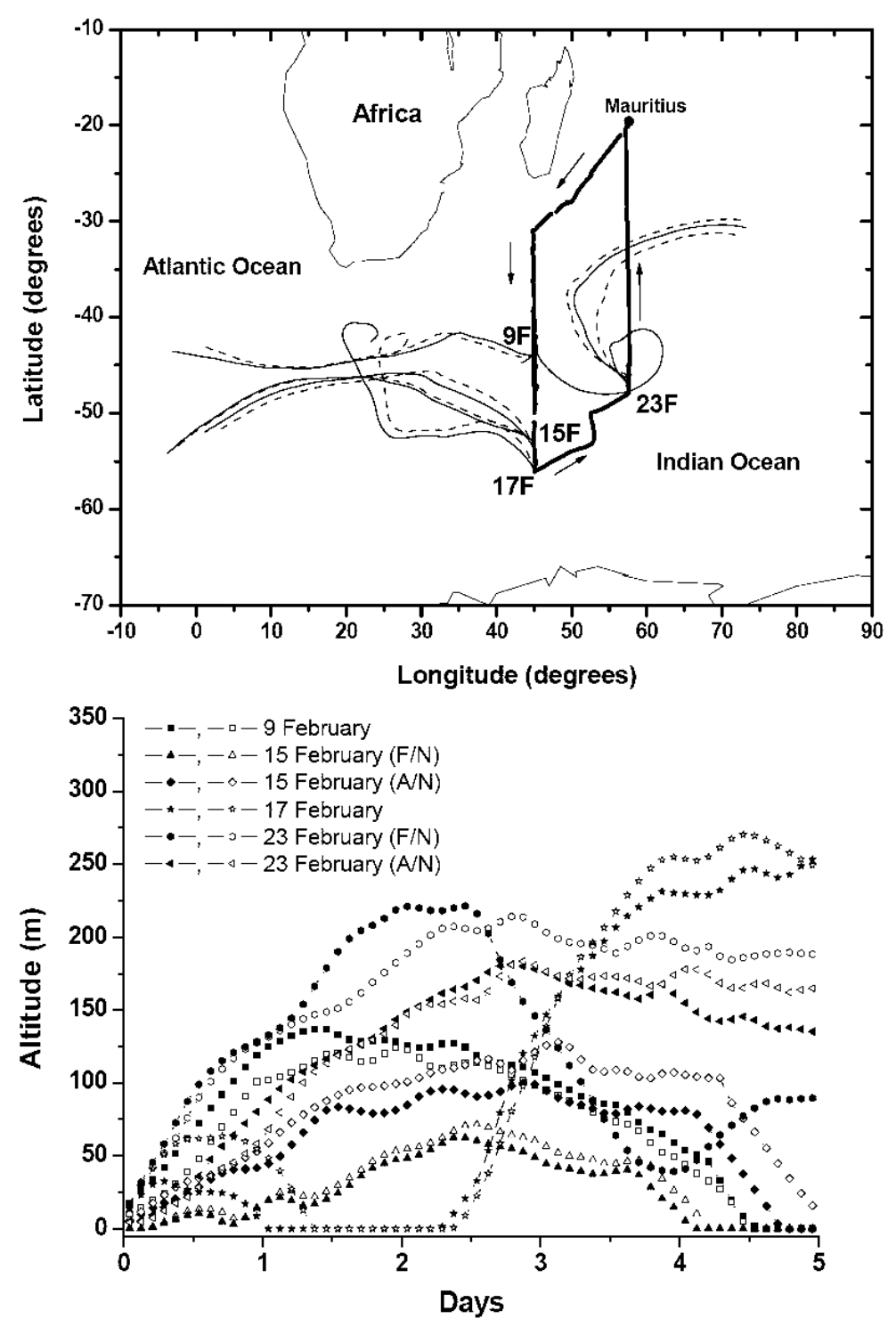

Figure 1. The 5-day back trajectories drawn on the cruise route (thick line) about 1-hour before (thin line) and after (dashed line) the six fog episodes. Altitude history of backward trajectories arriving at the measurement site before and after the fog episode are shown with solid and open symbols, respectively.

mode $(0.1<d<1.0 \mu \mathrm{m})$ and coarse mode $(d \geq 1 \mu \mathrm{m})$. Figure 2 shows the time-variation of contours of number size distributions of aerosol particles in the size ranges of $0.5-20 \mu \mathrm{m}$ diameter (6 cases in figure 2a) and 16-700 $\mathrm{nm}$ diameters ( 2 cases in figure $2 \mathrm{~b}$ ) for a few hours before, during and after the fog period. Measurements in the size range of $16-700 \mathrm{~nm}$ diameter particles could not be made during all cases of fog episode because of operational problems. The vertical dotted lines in each panel show the beginning and end of the fog period. However, these timings involve some subjectivity and need be taken only as guidelines as these are based on visual observations of atmospheric visibility. Air enters the tube at ambient value of the atmospheric relative humidity and undergoes a certain degree of drying during its passage through the instrument. Therefore, all particle sizes have been normalized to standard relative humidity of $80 \%\left(D_{80}\right)$ to compensate for the effects of the relative humidity changes (Zhang et al 2006).

In all the six cases, the aerosol size distributions plotted in figure 2(a), show a maximum at 0.8-1 $\mu \mathrm{m}$ diameter $1-2$ hours before the onset of fog. Thereafter, concentrations of all particles in this size range keep decreasing with time until 10-20 minutes before the onset of fog and the decrease is faster for particles of $>1 \mu \mathrm{m}$ diameter. Concentration of particles of all sizes, especially of $<1 \mu \mathrm{m}$ in diameter, starts increasing very rapidly 10-20 minutes before the onset of fog. This rapid increase in concentrations of submicrometer particles extends down to fine and ultrafine particles 
(a)

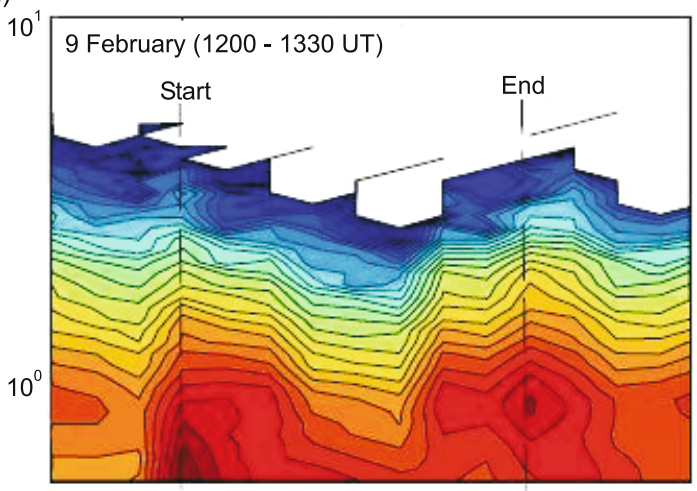

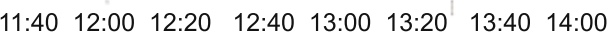
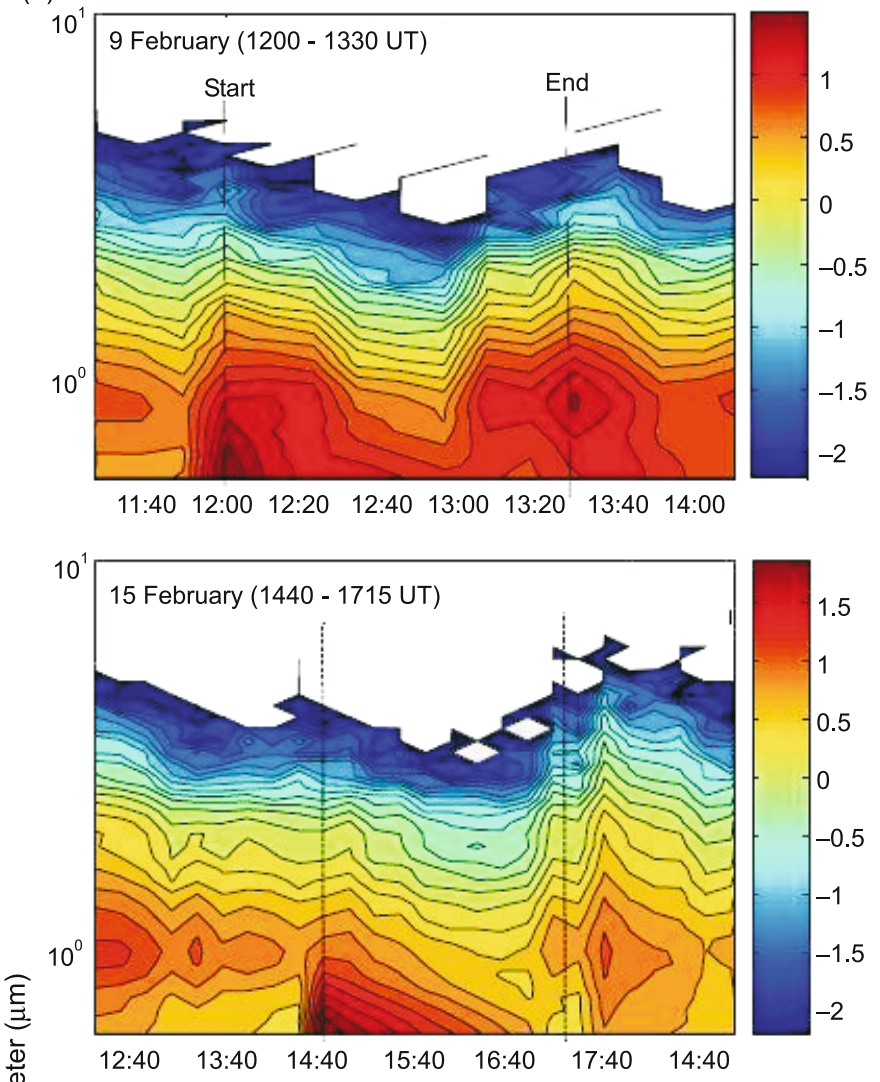

$10^{\circ}$
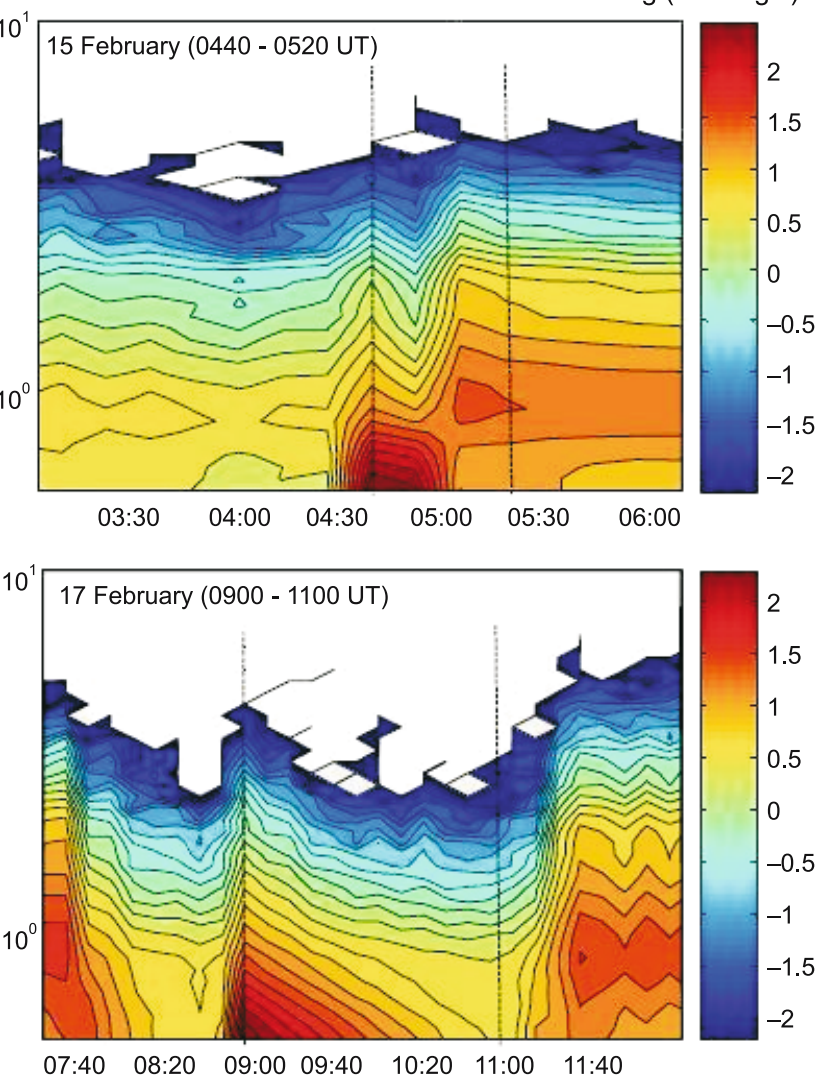

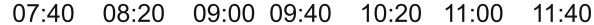
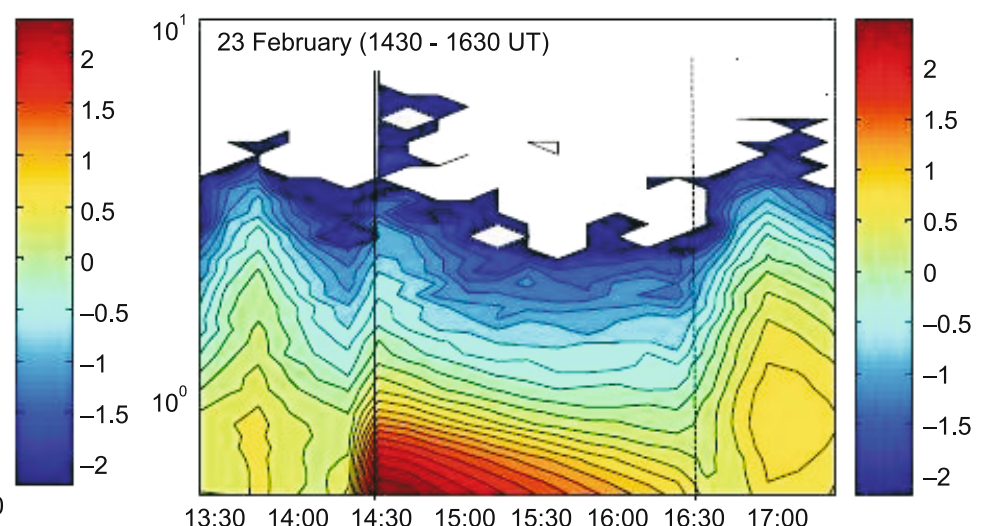

$\begin{array}{lllllllll}13: 30 & 14: 00 & 14: 30 & 15: 00 & 15: 30 & 16: 00 & 16: 30 & 17: 00\end{array}$
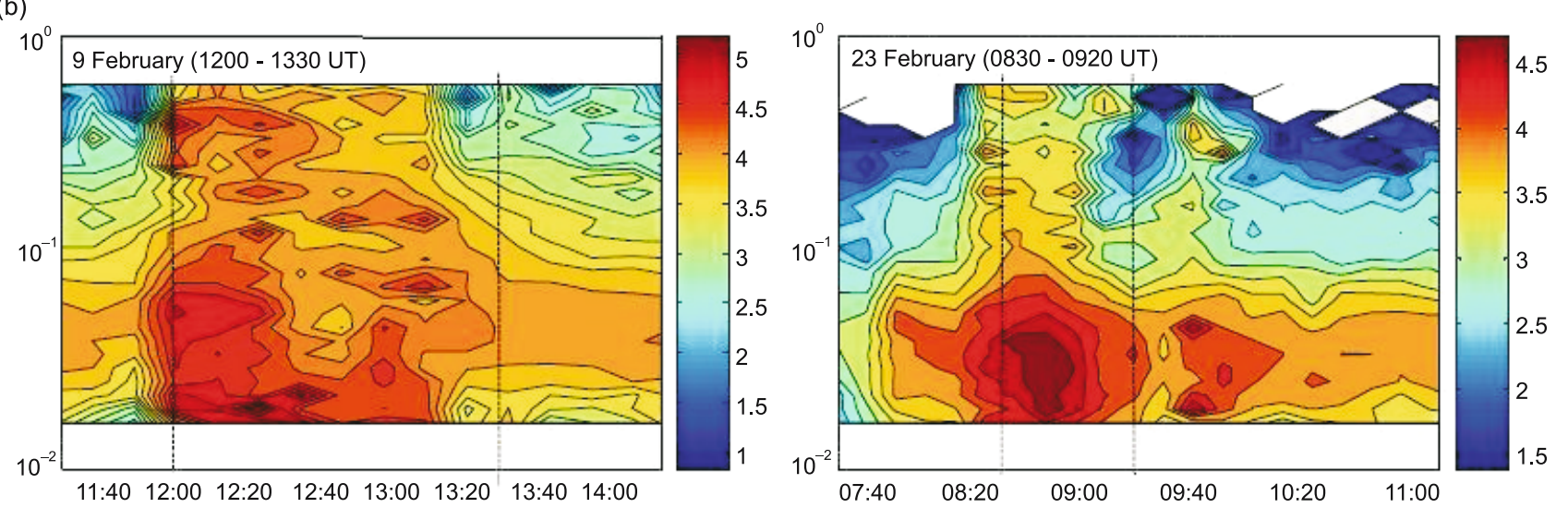

Time (UT)

Figure 2. Contour diagrams showing the time variation of number size distribution of aerosol particles in size ranges of 0.5-20 $\mu \mathrm{m}$ (a) and 16-700 nm (b). The vertical dotted lines show the beginning and end of the fog period. 

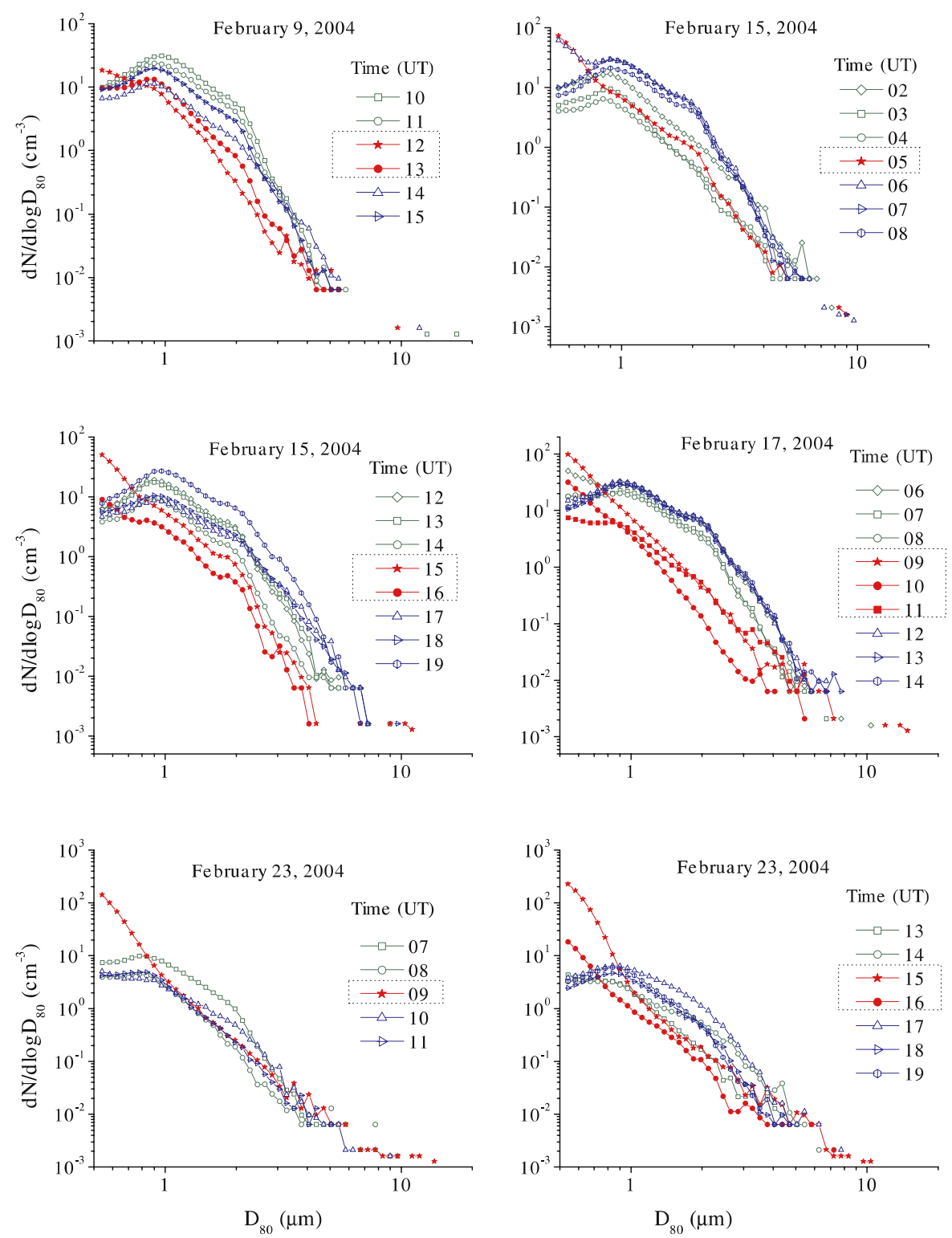

Figure 3. The hourly-averaged size distribution curves of aerosol particles for a few hours before, during, and after the fog period. The fog period is covered by the timings in the dotted box shown in each panel.

and is rather more prominent in case of nucleation and Aitken mode particles (figure 2b). The maxima for Aitken particles appears at 40-60 nm diameter. The increase in particle concentrations from pre-fog to fog periods is maximum on either side of this mode and is minimum in the $40-60 \mathrm{~nm}$ diameter size-range. Aerosol concentrations reach their maximum values in $<20$ minutes and then keep decreasing during the fog period. After the fog dissipation, the concentrations of coarse mode particles in figure 2(a) increase and soon return to their pre-fog levels but concentrations of Aitken mode particles in figure 2(b) decrease relatively slowly in returning to their pre-fog level.

The effect of fog is effectively illustrated in figure 3 which shows hourly-averaged size distribution curves of aerosol particles for a few hours before, during and after the fog periods. During the 1-2 hours period, both before and after the fog, the particle size distributions are bimodal with maxima at $0.8-1.0 \mu \mathrm{m}$ and $40-60 \mathrm{~nm}$ diameters. However, during the fog period, both maxima disappear and the size distributions nearly follow a power law.

\subsection{Total aerosol number and surface area concentrations}

Figure 4 shows variations in the number and surface area concentrations of particles of $>1 \mu \mathrm{m}$ and $<1 \mu \mathrm{m}$ (from 0.5 to $1 \mu \mathrm{m}$ ) diameters, measured with the APS system before, during, and after the fog episodes. In spite of comparatively small changes in the number concentration of particles 


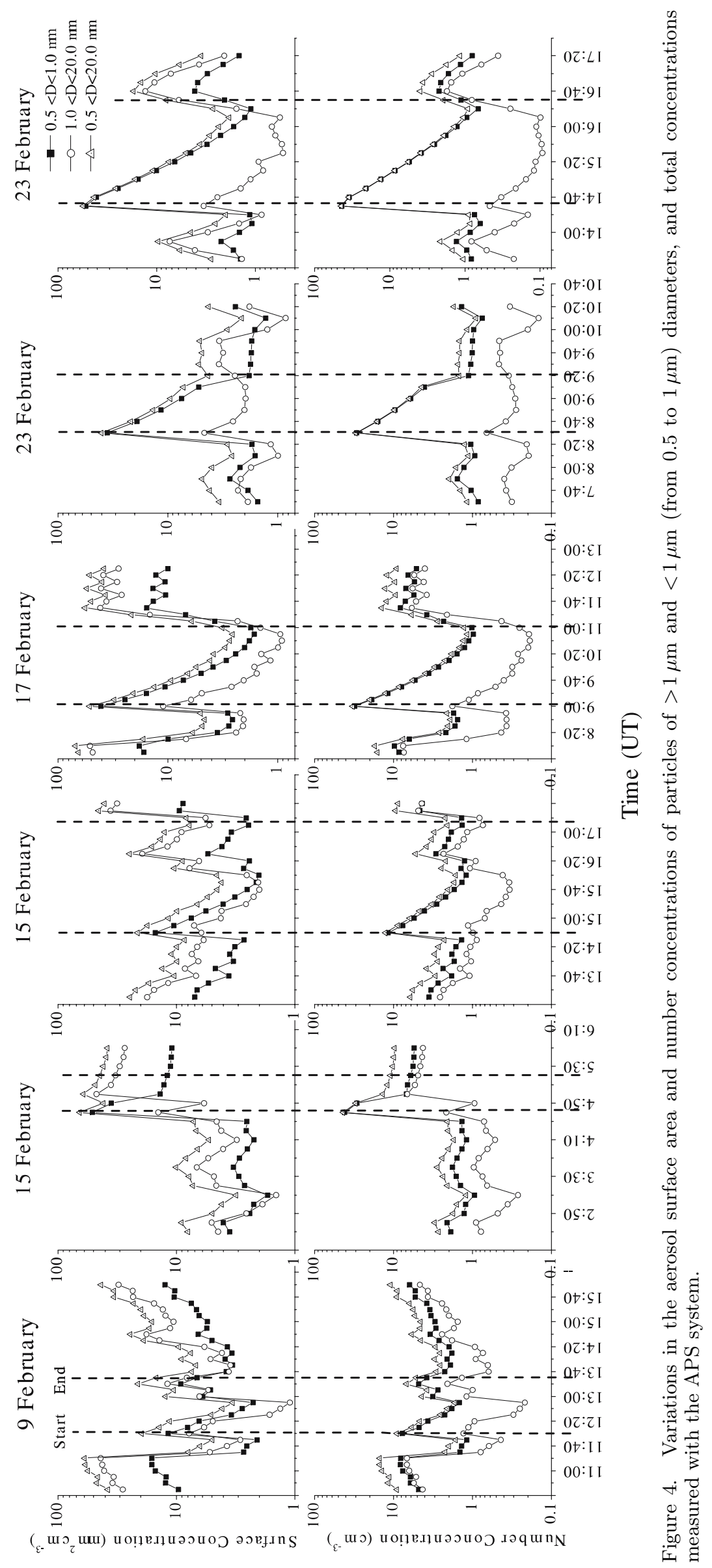


of $>1 \mu \mathrm{m}$ diameter, their large contribution to the changes in aerosol surface area is worth noting and will be further discussed in section 5 .

\section{Discussion}

Simultaneous measurements of chemical composition and fog particle characteristics are needed for a quantitative understanding of the aerosol size distribution changes discussed above. In the absence of such measurements, however, we propose the following hypothesis, based on well-known facts and the earlier measurements made during fog periods. Coarse particles preferentially act as condensation nuclei of sea-fog droplets rather than fine particles because of the effect of surface curvature (Sasakawa and Uematsu 2002). Therefore, more and more nuclei become activated and grow in an environment of high humidity. Larger particles not only grow faster but also fall faster and scavenge the slower moving smaller particles in their path. Analysis of the fogwater collected over sea also shows that sea fog scavenges the aerosol particles (Sasakawa and Uematsu 2002). Since aerosol particles $>1 \mu \mathrm{m}$ diameter are collected more efficiently than smaller particles of 0.1 to $1 \mu \mathrm{m}$ diameter in the Greenfield gap (Wang et al 1978) the decrease in number concentrations of coarse mode particles during fog periods, causes a large decrease in surface area of aerosol particles (figure 4). Therefore, the low vapour-pressure gases, which were being used for the growth of coarse particles, now become available for the rapid growth of smaller particles by the gas-phase and droplet-phase reactions. Moreover, the rates of the nucleation and growth of small particles are known to be greatly accelerated in the presence of $\mathrm{NH}_{3}$ and iodine oxide (e.g., Kulmala et al 2000; Saiz-Lopez et al 2007). Observations of Quinn et al (1992), Zhuang and Huebert (1996), Norman and Leck (2005) show that the ocean is a net emitter of $\mathrm{NH}_{3}$ in remote areas. For example, measurements of Norman and Leck (2005) over the remote Atlantic and Indian Oceans show the median gas phase ammonia concentrations of 0.02 to $0.055 \mu \mathrm{g} \mathrm{m}^{-3}$ which, occasionally increased to $0.138 \mu \mathrm{g} \mathrm{m}^{-3}$. Further, measurements of Putaud et al (1992) at Amsterdam Island in the southern Indian Ocean show that the average monthly concentrations of $\mathrm{SO}_{2}$ range from 0.013 to $0.25 \mu \mathrm{g} \mathrm{m}^{-3}$ and are minimum in winter and maximum in summer.

Observations of Clarke et al (1998) in the cloud outflow regions demonstrate that nucleation preferentially occurs when the existing aerosol surface area drops below $\sim 5-10 \mu \mathrm{m}^{2} \mathrm{~cm}^{-3}$. Our observations also show that the increase in number concentrations of the nucleation and Aitken mode particles starts only when the surface area of existing aerosols drops down to a minimum of $\sim 3 \mu \mathrm{m}^{2} \mathrm{~cm}^{-3}$ because of sedimentation of coarse particles (figure 4). Other conditions for the new particle formation by photochemical process are already fulfilled in the fog environment over the southern Indian Ocean. For example, Korhonen et al (1999) suggest that the thermodynamically stable clusters, available for subsequent growth, can form under typical atmospheric levels of $\mathrm{NH}_{3}$ and $\mathrm{H}_{2} \mathrm{SO}_{4}$. We suggest therefore, that the growth and subsequent settling of these clusters as larger particles on the sea surface in these regions provide a trigger for the new particle formation similar to that in outflow regions of cloud. Similar hypothesis has been proposed by Hoppel and Frick (1990) to explain their observations of the changes in aerosol size distributions after the passage of the ship through a region characterized by increased winds of variable direction, sharp increase in relative humidity, light fog and rain and through a frontal region. Presence of sufficient concentrations of $\mathrm{NH}_{3}$ in the marine boundary layer accelerates the growth of these particles by ternary reactions. Formation and growth of the newly formed particles just before the onset of fog, however, stop in $<20 \mathrm{~min}$ when the surface area provided by the newly formed particles increases and the low pressure gases are no longer available in sufficient concentrations to sustain the formation and growth of new particles. Thereafter, loss of particles by sedimentation will cause yet another but a slower decrease in aerosol surface area (figure 4). Finally, the number and surface area concentrations of particles settle down to pre-fog levels when the fog dissipates. Our hypothesis is supported by the fact that while the decreased concentrations of coarse particles during the fog period recover back to pre-fog levels soon after the fog dissipation, the enhanced concentrations of Aitken mode particles continue to exist, though at reduced levels, even 1-2 hours after the fog dissipation (figure 2). The observation indicates that even though the formation of new particles by nucleation process stops, the particles already formed and grown to larger sizes, continue to exist.

Our hypothesis is further supported by the fact that although the pre-fog total particle concentrations are very low on February 23, 2004 compared to other cases, still the fine particle concentrations increase to very high values during the fog period. Such an enhancement in fine particles is expected if the low vapour-pressure gases available after the decrease in coarse particles, are used for the growth of less number of particles.

In addition to observing similar trends in the changes in particle concentrations during the fog events at Davis, Moore et al (2004) observed a 
decrease in ammonium mass concentrations in particles of $>2 \mu \mathrm{m}$ diameter and an increase in smaller particles. However, their measurements were made with low size-resolution (10 channels over the range of $0.22-20.5 \mu \mathrm{m}$ diameter) and large sampling intervals (2 hours) which are not suitable for rapidly changing environments of fog. Moreover, anthropogenic sources at a continental station can provide additional low vapour pressure gases. During sea-fog events over the northwestern north Pacific Ocean, Sasakawa et al (2003) observed a decrease in the concentration of particles of $>0.5 \mu \mathrm{m}$ diameter but not much variation or even a slight decrease in the concentration of particles in the size range of $0.1-0.5 \mu \mathrm{m}$ diameter. In their analysis of six fog events, ionic concentrations of nitrate, nss-sulfate and ammonia decreased with time as the fog aged and the rate of decrease was observed to be higher for nitrate than ammonia and sulfate ions. Since nitrate exists on sea-salt particles in coarse mode (Kerminen et al 2000) and they serve as condensation nuclei for fog droplets to form and subsequently settle down to the surface, their concentration decreases faster. Non-observation of the increase in fine particles in measurements of Sasakawa et al (2003) may be because they were made over the northwestern north Pacific Ocean where the coarse particle concentrations before and even after the onset of fog remained an order of magnitude higher than in our measurements which were made in comparatively clean atmosphere of the Southern Hemisphere. Consequently, the availability of lowpressure gases even after the decrease in coarse particles, will not be sufficient for the formation and enhanced growth of new particles.

Our measurements of fine particles can be explained using the results of Ulevicius et al (1994) which show that diameter growth rate increases with increasing particle diameter for large particles of accumulation mode $(D>0.1 \mu \mathrm{m})$ but decreases with increasing particle diameter for smaller particles. They conclude that formation and growth of small particles is dominated by the growth resulting from condensation of low vapour pressure species by gas-phase reactions while growth of large particles $(>0.1 \mu \mathrm{m})$ is consistent with growth by droplet-phase (heterogeneous) chemical reactions.

The net effect of a fog episode is to change the modal distribution of aerosols over remote oceans to a power law size distribution. This change occurs in foggy weather by lowering the large and coarse mode particle concentrations by the sedimentation and preferential scavenging processes, and raising the accumulation and nucleation mode particle concentrations by enhancing their rates of growth and formation of new particles.
The occurrence of fog over remote oceans can, therefore, be considered as a source as well as sink of aerosols. Each sequence of fog episode may first create conditions for the depletion of coarse particles and then for enhancement of the growth and formation of the accumulation and nucleation mode particles. Net effect of each episode will thus modify the aerosol size distribution. Since the fog episodes occur quite frequently over open oceans, especially where the warm moist air passes over cold water, last for several hours, and may advect over several tens of kilometers, their contributions as source/sink of aerosols need be assessed on global scale for correct estimation of the radiation budget.

Present observations help to explain several systematic changes in the atmospheric electric conductivity proposed by many investigators to forecast the onset and dissipation of the marine fog (Serbu and Trent 1958; Dolezalek 1962; Deshpande and Kamra 2004). During the 1-2 hours period before the onset of fog, the coarse particles falling down to the sea surface, will scavenge the ions and charged aerosols in their path and thus decrease the electrical conductivity of the air. On the other hand, in the 1-2 hours period before the dissipation of fog, the concentration of fine particles systematically decreases from their enhanced level, which will slow down ion-aerosol attachment process and thus cause an increase in the lifetime of small ions and, therefore increase in the electrical conductivity of the air. This criterion can, therefore, be used for prediction of the onset and dissipation of marine fog.

\section{Acknowledgements}

Authors acknowledge the National Centre for Antarctic and Ocean Research, Goa for participation in the PESO expedition, the India Meteorological Department for providing the meteorological data and the NOAA Air Resources Laboratory (ARL) for the provision of the HYSPLIT transport and dispersion model and READY website (http://www.arl.noaa.gov/ready.html).

\section{References}

Clarke A D, Davis D, Kapustin V N, Eisele F, Chen G, Paluch I, Lenschow D, Bandy A R, Thornton D, Moore K, Mauldin L, Tanner D, Litchy M, Carroll M A, Collins J and Albercook G 1998 Particle nucleation in the tropical boundary layer and its coupling to marine sulfur sources; Science 282 89-92.

Clarke A D, Davis D, Kapustin V N, Eisele F, Chen G, Paluch I, Lenschow D, Bandy A R, Thornton D, Moore K, Mauldin L, Tanner D, Litchy M, Carroll M A, Collins J and Deshpande C G and Kamra A K 2004 The 
atmospheric electric conductivity and aerosol measurements during fog over the Indian Ocean; Atmos. Res. 70 77-87.

Deshpande C G and Kamra A K 2004 The atmospheric electric conductivity and aerosol measurements during fog over the Indian Ocean; Atmos. Res. 70 77-87.

Dolezalek H 1962 The atmospheric electric fog effect; Rev. Geophys. 1 231-282.

Hoppel W A and Frick G M 1990 Submicron aerosol size distributions measured over the tropical and South Pacific; Atmos. Environ. 24A 645-659.

Kerminen V M, Teinila K and Hillamo R 2000 Chemistry of sea-salt particles in the summer Antarctic atmosphere; Atmos. Environ. 34 2817-2825.

Korhonen P, Kulmala M, Laaksonen A, Viisanen Y, McGraw R and Seinfeld J H 1999 Ternary nucleation of $\mathrm{H}_{2} \mathrm{SO}_{4}, \mathrm{NH}_{3}$ and $\mathrm{H}_{2} \mathrm{O}$ in the atmosphere; J. Geophys. Res. 104(D21) 26,349-26,353.

Kulmala M, Pirjola L and Makela J M 2000 Stable sulphate clusters as a source of new atmospheric particles; Nature 404 66-69.

Moore K F, Sherman D E, Reilly J E and Collett Jr J L 2004 Drop size dependent chemical composition in clouds and fogs; Atmos. Environ. 38 1389-1402.

Norman M and Leck C 2005 Distribution of marine boundary layer ammonia over the Atlantic and Indian Oceans during the Aerosols99 cruise; J. Geophys. Res. 110 D16302, doi:10.1029/2005JD005866.

Pant V, Deshpande C G and Kamra A K 2008 On the aerosol number concentration-wind speed relationship during a severe cyclonic storm over south Indian Ocean; J. Geophys. Res. 113 D02206, doi: 10.1029/ 2006JD008035.

Pant Vimlesh, Deshpande C G and Kamra A K 2009 The concentration and number size distribution measurements of the Marine Boundary Layer aerosols over the Indian Ocean; Atmos. Res. 92 381-393.

Putaud J P, Mihalopoulos N, Nguyen B C, Campin J M and Belviso S 1992 Seasonal variations of atmospheric sulfur dioxide and dimethylsulfide concentrations at Amsterdam Island in the southern Indian Ocean; J. Atmos. Chem. 15 117-131.

Quinn P K, Asher W E and Charlson R J 1992 Equilibria of the marine multiphase ammonia system; J. Atmos. Chem. 14 11-30.

Saiz-Lopez A, Mahajan A S, Salmon R A, Bauguitte S J B, Jones A E, Roscoe H K and Plane J M C 2007 Boundary layer halogens in coastal Antarctica; Science $\mathbf{3 1 7}$ 348-351.

Sasakawa M and Uematsu M 2002 Chemical composition of aerosol, sea fog, and rainwater in the marine boundary layer of the northwestern North Pacific and its marginal seas; J. Geophys. Res. 107(D24) 4783, doi:101029/2001JD001004.

Sasakawa M, Ooki A and Uematsu M 2003 Aerosol size distribution during sea fog and its scavenge process of chemical substances over the northwestern North Pacific; J. Geophys. Res. 108(D3) 4120, doi:101029/2002JD002329.

Serbu G P and Trent E M 1958 A study of the use of atmospheric electric measurements in fog forecasting transactions; Amer. Geophys. Union $\mathbf{3 9}$ 1034-1042.

Ulevicius V, Trakumas S and Girgzdys A 1994 Aerosol size distribution transformation in fog; Atmos. Environ. 28 795-800.

Wang P K, Grover S N and Pruppacher H R 1978 On the effect of electric charges on the scavenging of aerosol particles by cloud and small rain drops; J. Atmos. Sci. 35 1735-1743.

Zhang K M, Knipping E M, Wexler A S, Bhave P V and Tonnesen G S 2006 Reply to comment on "Size distribution of sea-salt emissions as a function of relative humidity"; Atmos. Environ. 40 591-592.

Zhuang L and Huebert B J 1996 Lagrangian analysis of the total ammonia budget during Atlantic Stratocumulus Transition Experiment/Marine Aerosol and Gas Exchange; J. Geophys. Res. 101(D2) 4341-4350. 